BOOKS

\section{Physician heal thyself}

Benevolence

Cynthia Holz

Alfred A. Knopf; 2011

$\mathrm{W}$ hat if the doctor seeks a cure from the patient? This premise provides the narrative drive for novelist Cynthia Holz's latest book. She executes her stratagem with three highly believable central characters: psychologist Renata Moon, psychiatrist husband Ben Wasserman and Ben's mother Molly. The marriage has lost its spark. Where to turn for help? Molly? Introspection? Psychotherapy? Of course not. To patients.

I often found myself angry at both doctors, yet found Holz's depictions believable. Their lack of self-awareness smacks of credibility because Ben provides no therapy, while Renata engages patients only through in vivo desensitization. Both of them are knowledgeable about "biologism" and "behaviourism," but neglectful of psychoanalytic concepts. Yet developmental ego psychology and transference are their issues. The case for transference is most straightforward.

We never doubt Ben's accustomed competence as a psychiatrist member of a kidney transplant team. His current assignment involves an evaluation of Arthur Rae, who has volunteered to donate his kidney to a neighbour. Though neglecting the term in internal dialogue, Ben probes for "transference," and whether some past significant relationship (a loss or unresolved relationship with a family member) could affect Arthur's apparent altruism and, in particular, shape his perception of Ben.

Three signals should have warned Ben about transference. Arthur's insistence on a nonprofessional home visit from Ben arises from a past life situation. And when the kidney recipient halts the process, Arthur's excessive dismay clearly indicates some unresolved need. The third evidence of transference is Ben's conviction that Arthur possesses special knowledge to impart. Ben is smitten with "countertransference,"
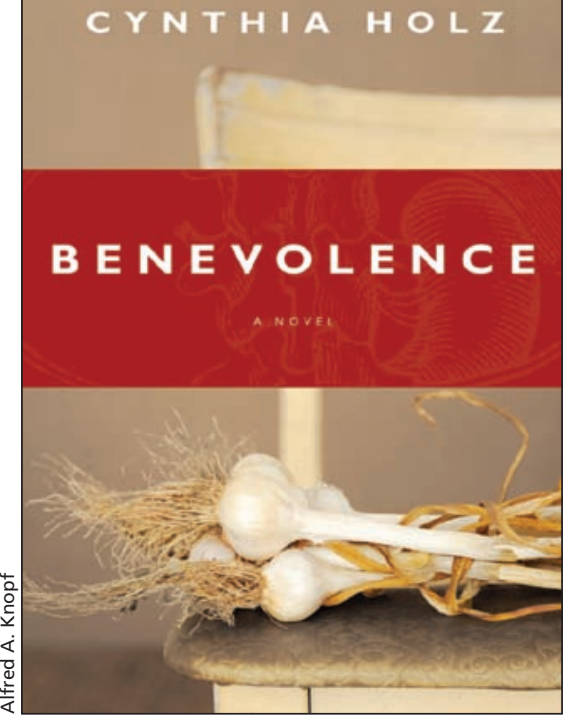

which indicates both unresolved conflict within the doctor and an emotional response to a wish from the patient.

When Arthur tells Ben about a concealed motivation that could have brought harm to Arthur had the transplant proceeded and failed, Ben neglects the mental exercise familiar to anyone conversant with transference and countertransference: analyze why he missed it.

It takes little reflection to realize that every consideration of risk and benefit hinges on transference. Does the patient expect something that the treatment cannot provide? Physicians can't know all answers, but should always consider possible patient transference, and countertransference within themselves.

Renata's patient Stella presents an opposite dilemma. Throughout the treatment, Renata is wracked with doubt about becoming "too close" to Stella. Yet even a home visit proves therapeutic because, at her developmental level, Stella needs a real parent. In other words, Renata concentrates on therapeutic neutrality as an empty rule, ignoring Stella's emotional development, the next topic.

As outlined by Erik Erikson, life proceeds in sequential developmental ego psychology stages, each (intimacy combined with work) the basis for the next. In Ben's case, his current stage (generativity v. stagnation) is plagued by residual issues from adolescence (identity v. identity confusion.)

Ben's countertransference illustrates how developmental psychology and transference are always intertwined. He turns to Arthur to understand his own conflict, the interaction between his career as a doctor and his relationships with his parents and Renata. At the exact moment Ben realizes what he neglected in Arthur's history, the psychiatrist comes face to face with the critical moment in his own psychological development, one never processed, a moment when Molly proved her special love for him by defending his career choice. Comprehending Arthur's conflict leads to Ben's own comprehension.

Ben got it backwards. Doctor, understand your own developmental psychology, then detect conflicts in the patient.

Which brings up Ben's mother. Molly's diagnosis of the problem:

Ben was a worrier who didn't have enough of Molly's good sense or wisdom. He wanted a family with cut-out dolls for his mama and papa and snuggly babies on his knee - which was just foolishness. Life's a twisty-turny thing and all you get, if you're lucky, is a slice of what you hoped for. If only he understood that living's hard for everyone, not just him, ... maybe he'd be thankful for his smart and pretty wife, his job where he saves lives.

How can uneducated Molly get it about finding meaning and joy in life when her son and daughter-in-law, the doctors, don't? Is it too glib to say they neglected emotional development for professional success? Attention to developmental psychology — our own — offers a remedy.

Who should read this book? The author has neglected depth in literature, as Renata and Ben neglected it in psychology/medicine. That said, this novel would be an ideal vehicle for teaching medical students or residents to identify transference and developmental psychology within themselves and their practices. Any physician willing to confront difficulty in attending to personal emotional health will benefit, if braced for some discomfort, as the novel strikes some less positive notes about us. Physician heal thyself.

\section{Rick Whitten-Stovall MD ABPN \\ Psychiatrist \\ Albany Medical Clinic \\ Toronto, Ont.}

CMAJ 2013. DOI:10.1503/cmaj.111313 